\title{
THE METHOD OF EVALUATION OF THE AIRCRAFT CONTROL SYSTEM
}

\section{T. Rogalski, B. Dołęga}

Rzeszow University of Technology, Rzeszow, Poland.E-mail: orakl@prz.rzeszow.pl, dolbog@prz.rzeszow.pl Received 1810 2004, accepted 10062005

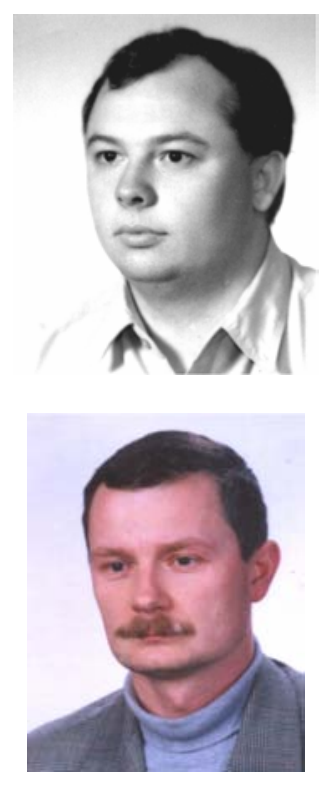

Tomasz ROGALSKI, $\mathrm{PhD}$

Date and place of birth: 1972 in Tarnow, Poland.

Education: 1996 - Reshow University of Technology.

Affiliations and functions: 1996 - Present - Aviation Department of Reshow University of Technology.

Research interests: Pilot friendly control system for small transportation plane.

Publications: About 30 articles.

Boguslaw DOLEGA, PhD

Date and place of birth: 1962 in Jaslo, Poland.

Education: Rzeszow University of Technology.

Affiliations and functions: Rzeszow University of Technology, assistant; 1994 - PhD degree from the Department of Mechanical Engineering of Rzeszow University of Technology; since 1995 - Professor Assistant on Avionics and Control Systems Department at that University.

Research interests: Diagnostics aircraft navigation and control systems, with a focus on the development of the control theory for online fault detection and localization methods.

Experience: Co-organizer of Avionics Conferences.

Publications: Over 40 scientific articles.

Present position: Professor Assistant on Avionics and Control Systems Department at that University.

Abstract. The dynamical development of general aviation demands compilation of new aircraft control methods. Those methods allow people without special airborne qualifications to pilot these aircrafts. The main goals of such a control system are to reduce a pilot's load, to improve control precision, and to protect an aircraft against dangerous situations. There are many criterions applied to grading and describing an aircraft's flying characteristics and the handling qualities of general aviation airplanes equipped with classical mechanical control systems. But a modern, small, transport aircraft should be equipped with fly-by-wire control systems, and there are no clear, straight, rules rate and describe the handling qualities of small airplanes with fly-by-wire control systems.

This paper presents a methodology created by the authors that classifies and compares the handling qualities of general aviation aircraft equipped with fly-by-wire control systems. It takes into consideration two parameters: pilot's effort during realization of ordered tasks and precision of his control.

The methodology presented was tested during real operational conditions on a small, four-seat airplane, the PZL-110. Sample results reached during flight tests are included.

Keywords: aircraft control system, handling qualities, flight tests.

\section{Introduction}

Investigations of control systems for small transportation aircraft have been performed for a few years at the Avionics Department of Rzeszow Technical University $[2,1]$. A control system that allows modifying

an airplane's handling characteristics has recently been projected, prepared, and tested $[7,4,5]$. During this activity, the main goal of the Avionics Department was to build a control system for small transport aircraft and to create a methodology to rate the work of such control system [3].

Some reasons why fly-by-wire control systems for small transport aircrafts are constructed are to reduce a pilot's load and to improve the precision of maneuvers performed by pilots. They have become the base to formulate rules allowing grading the manual-computer- aided control systems. In this case the pilot manually controls the plane but an on-board computer corrects actions taken by a human to improve the plane's responses (Fig 1).

There are two factors used to rate the handling qualities of an aircraft in the methodology presented in this paper. The pilot's load factor and precision of control are the parameters, which can be used to evaluate the work of control systems considered in this paper.

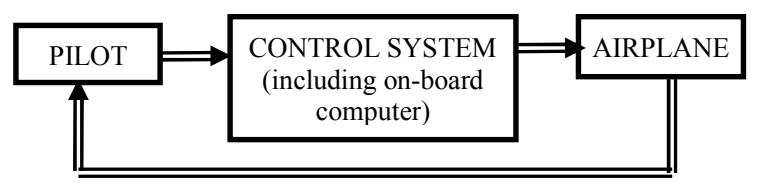

Fig 1. The schematic of manual-computer-aided control system 


\section{The methodology of evaluation aircraft's handling qualities}

Medicine, ergonomics or other scientific disciplines tell how to measure the pilot's load. But those methods are not available or too complicated to be done flight on the board of small aircraft. It was necessary to introduce maybe less accurate but simpler one criteria. The proposed criteria must also enable the handling qualities of airplane not equipped with specialized instruments, using only internal elements of the control system to be rated. Additionally, all measurements must be done during a plane's normal operational conditions.

Interviews with pilots and investigations with a specialized laboratory stand were conducted [3, 6]. Their task was to define the level of the pilot's load. Finally, the relation between a pilot's effort necessary to perform the demanded maneuver and both the number and character of movements of the control device (e.g. a stick, a side stick or a control wheel) was found. The number of movements of the control device during the time units and their amplitude can approximately describe the pilot's effort.

To measure a pilot's effort, a parameter $J(1)$ was created. Its value depends on the number and the amplitude of control devices and can approximately define either a pilot's effort or a pilot's load level.

$$
J=\frac{n \sum_{i=1}^{n} M_{i}}{t_{c}} ; \quad \mathrm{t} \in\left(0, \mathrm{t}_{\mathrm{c}}\right)
$$

where:

$$
\begin{array}{ll}
\mathrm{n} & \text { - number of movements, } \\
\mathrm{M}_{\mathrm{i}} & \text { - amplitude of } \mathrm{i} \text {-th movement, } \\
\mathrm{T}_{\mathrm{c}} & \text { - observation time. }
\end{array}
$$

Both the number and amplitudes of movements were measured according to the schematic presented on

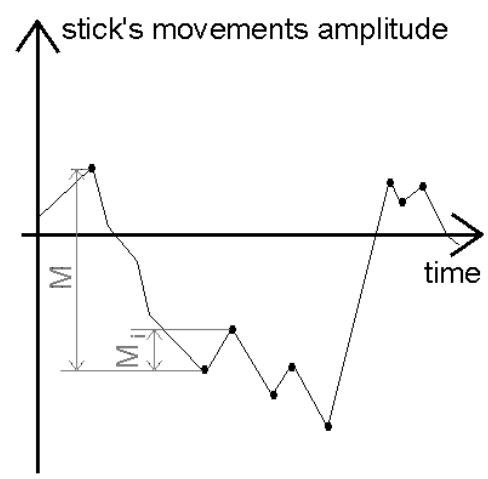

figure 2 .

Fig 2. The schematic of control device's displacement measurement

Major pilot's load should cause more movements of the control device and its bigger amplitudes. These phenomena influence into the value of the pilot's load factor (1).
The second parameter determinates the grade of the tested control system and a precision of control realized by the pilot.

If we analyze the set of maneuvers realized by pilots during typical operational conditions, we can see that there are two main kinds. The first group consists of stabilization maneuvers of selected flight parameters (altitude, speed, pitch angle, etc.). The second group consists of maneuvers interception of the demanded flight parameters (as in stabilization processes).

In the case of stabilization maneuvers the most important problem is to precisely keep the demanded flight parameter. The precision of the control process can be described well enough by a parameter called "stabilization error" defined by either formula (1) or (2).

$$
\begin{aligned}
E_{1}=\sqrt{\frac{\int_{0}^{t_{i}}\left(p-p_{d}\right)^{2} d t}{t_{i}}} \\
E_{2}=\frac{\int_{0}^{t_{i}}\left|p-p_{d}\right| d t}{t_{i}}
\end{aligned}
$$

where:

$$
\begin{aligned}
& \mathrm{P}-\text { real value of the stabilized flight parameter, } \\
& \mathrm{p}_{\mathrm{d}} \quad-\text { demanded value of the stabilized flight } \\
& \text { parameter, } \\
& \mathrm{t}_{\mathrm{i}} \quad \text { - integration time (observation time), } \\
& \mathrm{E} \quad \text { - stabilization error (value of parameter } \\
& \text { describing control precision). }
\end{aligned}
$$

To stabilize a new demanded value of the selected flight parameter, the pilots expect that all temporary processes are as short as possible. In other words, they want the regulation time to be as short as possible.

Now it is possible to prepare a special diagram, which by using the parameters introduced above (regulation error, regulation time and pilot's effort), graduates and compares manual-computer-aided control systems mounted in the aircraft (Fig 3).

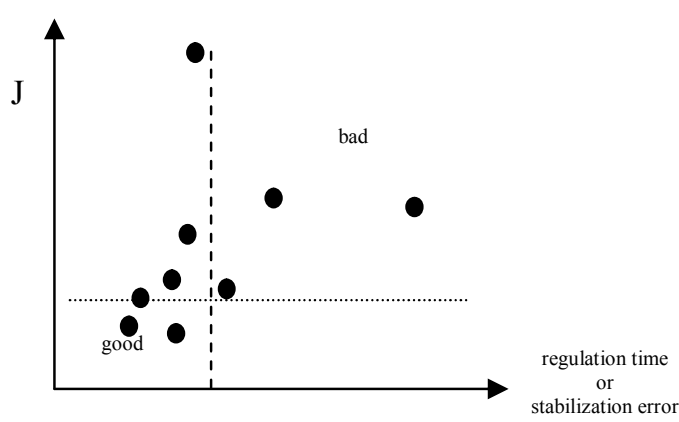

Fig 3. The diagram presenting plane's handling qualities

$\mathrm{X}$-axis represents the value of the time of regulation or the error of stabilization depending on the considered maneuver (Fig 2). The Y-axis represents the pilot's effort (1). Then location of the symbol representing the tested control system in this axis system depends on the 
handling qualities of the control system. The solution described above allows the handling qualities of airplanes equipped with tested control systems and presents results in a simple form.

There are marked areas defining aircraft's handling qualities in Figure 2. Airplanes represented by marks lying the nearest to origin of axis system have handling qualities described as the best ones. It means, cases with small value of pilot's effort factor and small value of the error of stabilization or the short regulation time.

\section{Experimental control laws}

The criteria presented in this paper were used to grade the handling characteristics of a light plane. The handling qualities of a PZL-110 airplane equipped with an SPS-1 control system working according to the following kinds of controls (modes of control) were tested [3].

1. Mode one. Deflections of control surfaces were proportional to the position of the control device. Extreme displacements of the control device brought extreme, permitted deflections of control surfaces. This mode of work was also called "direct proportional control".

2. Mode two (Fig 4). Deflections of control surfaces were calculated by special forming functions. Those functions considered both the displacement of a control device and the rate of a pilot's hand movement. In this case also extreme displacements of the control device led to extreme, permitted deflections of control surfaces.

3. Mode three (Fig 5.). Specially prepared regulators of selected flight parameters were used during the control of the airplane's spatial attitude. The positions of control surfaces did not directly depend on a pilot's action but were calculated by a regulator system. In this case, a pilot's role was only to demand flight parameters. The rest was realized by the system of stabilization of the selected flight parameter that was used in that case.

It is worth noticing that there is no direct feedback between the state of the plane and the control system in the two first cases. Both the plane's dynamics and pilot's impressions close the control loop. Only mode three has direct feedback from the state of the plane to the control system.

As a control device to control the flight of the experimental airplane, the mini side stick was used. The longitudinal and lateral displacements of the side stick affected aircraft's motion mode. The horizontal roll of the handle replaced the classical control processed by the rudder.

\section{Sample results of flight tests}

Projected algorithms modifying aircraft handling qualities were tested in flight tests. Several flights were performed. During them, the pilot did a number of established maneuvers. They were programmed of the aircraft such a way to check the handling qualities during typical operational conditions. There were course and altitude catching and stabilization, different kinds of climbing and descending, coordinated turns, and other processed maneuvers.

Samples illustrating results reached during flight tests of the SPS-1 fly-by-wire control system are presented in this chapter. For the longitudinal mode of movement of an airplane, the maneuver of catching and stabilizing the flight altitude was selected and for the lateral mode the course stabilization maneuver were used to analyze the flight characteristics. During the test flight, the pilot controlled the airplane using different control laws. Recorded flight parameters allowed the aircraft's handling qualities to be according to the methodology presented in this paper.

Control laws in the longitudinal channel of motion considered during these flight tests had the following forms:

\section{Control surfaces's position during stable, horizontal flight}

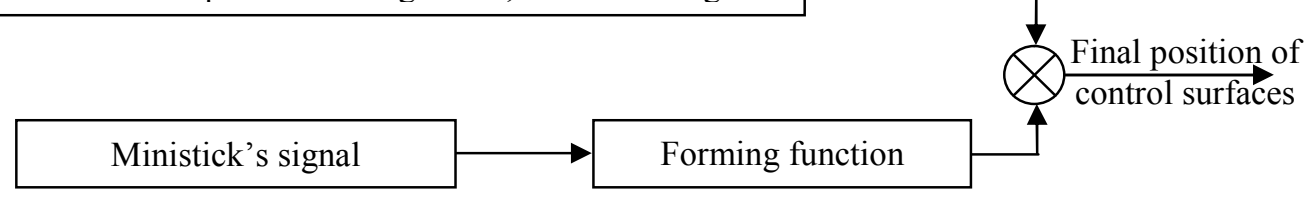

Fig 4. The schematic of control law using forming functions

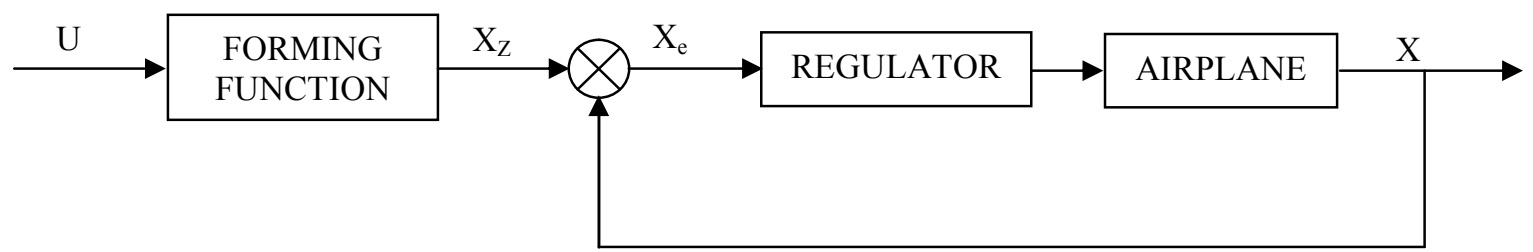

Fig 5. The schematic of control laws using regulators of selected flight parameters. $U$ - ministick's position, $X$ - stabilized value of selected flight parameter, $X_{z}$ - demand value of stabilized flight parameter, $X_{e}-$ stabilization error 
1. Direct proportional control when the deflection of the elevator was proportional to the displacement of the side sticks. For safety reasons, to prevent the airplane against overly dynamical maneuvers, the maximum deflection of the elevator was restricted to \pm 7.5 [deg], from the position needed to keep straight, horizontal flight (value chosen experimentally). It was necessary because a wider range (bigger proportional coefficient) caused the airplane to be too difficult to be fly by.

2. The control law including the forming functions. - In this case, the position of the elevator $\delta E$ was calculated according to formula (4) on the basis of the side stick's position $X_{s}$. The range of the deflections of the elevator was restricted as for the proportional control law.

$$
\delta E=\operatorname{sgn}(X s) \cdot 7.5\left(\frac{X s}{100}\right)^{2}
$$

3. That control law was based on the PID regulator of pitch angle. The forming filters preparing demand value of pitch angle kept by the regulator, worked as follow (5).

$$
\Theta_{d}=\left.k \int X_{s} d t\right|_{\Theta \min } ^{\Theta \max }
$$

where $\Theta_{\mathrm{d}}-$ demanded value of pitch angle,

$\mathrm{k}$ - integration coefficient,

Xs - the displacement of the stick,
$\Theta_{\min }, \Theta_{\max }-$ minimum and maximum permitted pitch angles.

Such a form of the control algorithm caused appearing of the rate of the pitch angle, which was proportional to a side stick's position. Putting the side stick into the neutral position stopped rotation, and the computer kept the fixed value of pitch angle.

Finally, the pilot moving the side stick gave to the control system value of pitch angle, which was stabilized by the regulator.

In the lateral channel of airplane motion, control algorithms had the same form as in the longitudinal one. But they concerned respectively the aileron's displacement and bang angle control in the third case of tested control laws.

The slide slip angle was automatically reduced to zero by the regulator system. The pilot did not need to take any action to do that.

Here are only a few selected samples illustrating effects that came after the described control laws had been implemented into the onboard computer.

Figures 6 and 7 present selected fragments of flights, when the pilot controlling the plane tried to stabilize the altitude. Data recorded during those tests allowed, according to methodology included earlier in this paper, coefficients defining both control precision (2), (3) and pilot's effort (1) to be calculated. Sample results presenting changes of those parameters were collected and put into Table.

Table . Differences of pilot's effort and coefficients defining control precision for tested control algorithms

\begin{tabular}{|c|l|c|c|c|}
\hline $\begin{array}{c}\text { Parameter's } \\
\text { symbol }\end{array}$ & \multicolumn{1}{|c|}{ Parameter [unit] } & $\begin{array}{c}\text { Direct } \\
\text { proportional } \\
\text { control }\end{array}$ & $\begin{array}{c}\text { Control with the } \\
\text { forming } \\
\text { function }\end{array}$ & $\begin{array}{c}\text { Control with } \\
\text { the controller } \\
\text { of pitch angle }\end{array}$ \\
\hline$E_{2}$ & Stabilisation error [m/s] & 1.4 & 1.6 & 1.6 \\
\hline$J$ & Pilot's effort $[\% / \mathrm{s}]$ & 52 & 27 & 0.3 \\
\hline
\end{tabular}

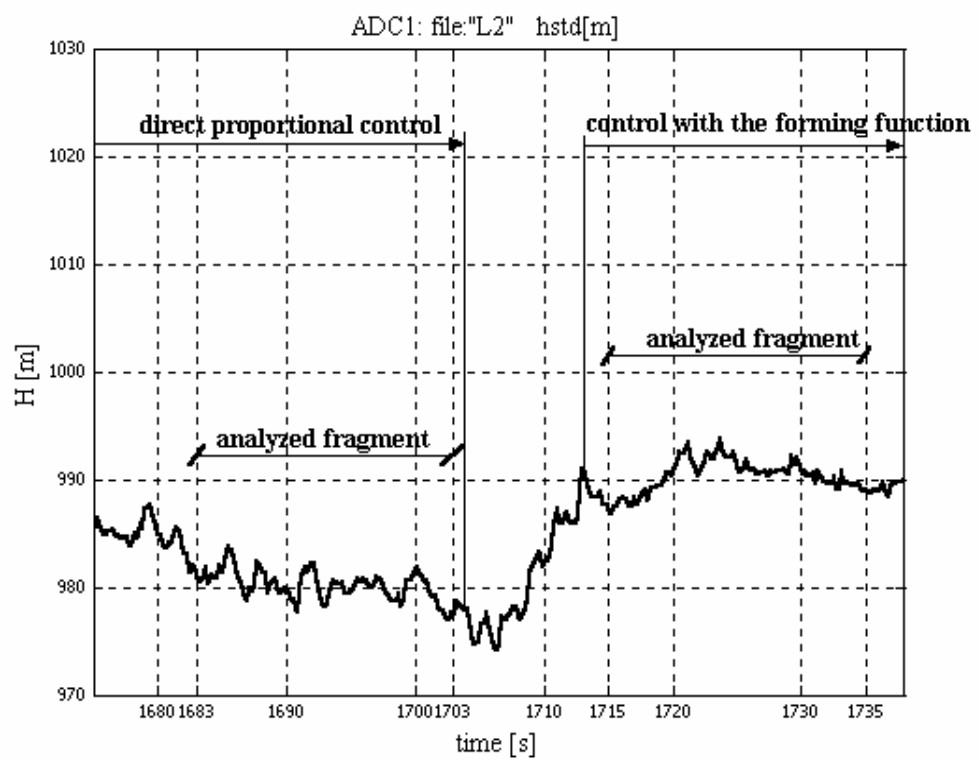

Fig 6. The selected fragment of flights when the pilot kept the altitude using direct proportional control and control law including forming function 


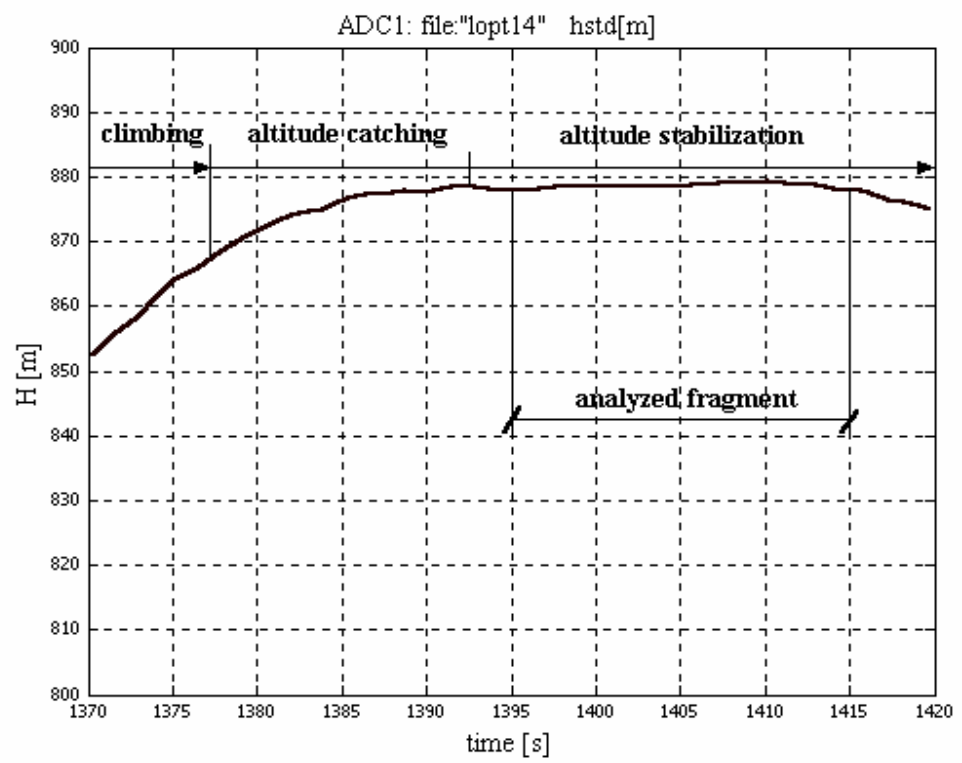

Fig 7. The altitude catching and stabilizing using the third mod of control (with PID pitch angle regulator and forming filter)

On the basis of the data presented, the following statements can be formulated. The control law using only a forming function (the second mode of control) little improves the precision of the test maneuver in comparison with direct proportional control. The flight was more stable with smaller amplitude of altitude changes. The number of the pilot's movements with the side stick was also lower. It led to a better (lower) value of coefficient pilot effort. More significant changes can be observed for the most advanced control law (with the pitch angle controller). In this case, a clear pilot load coefficient reduction appeared.

The foregoing results led to the following diagram allowing flying qualities of aircraft controlled with different control laws to be graphically compared (Fig 8).

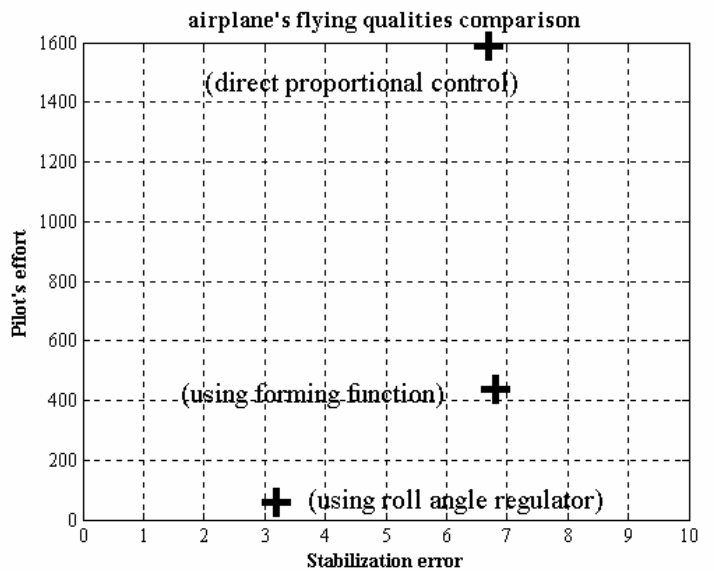

Fig 8. A comparison of aircraft handling qualities during altitude stabilization if tested control laws were used

Analyzing figure 8 , it can be noticed that more advanced control laws brought a reduction in the effort of a pilot's required to perform a certain maneuver. In the result, the point representing the flying qualities of a plane controlled via the algorithm using the pitch angle regulator lies the nearest to the origin of the coordinate system. It allows supposing that pilots should recognize the case of control as the best one.

A similar approach was realized to evaluate aircraft's flying qualities in lateral mode of plane's movement. As a test maneuver, course stabilization was selected. Sample results received during flying tests are presented on figure 9. Also in this case the most of advanced algorithms led the marker indicating aircraft's characteristics the nearest to the origin of the coordinate system. It meant the best flying qualities among all tested control laws.

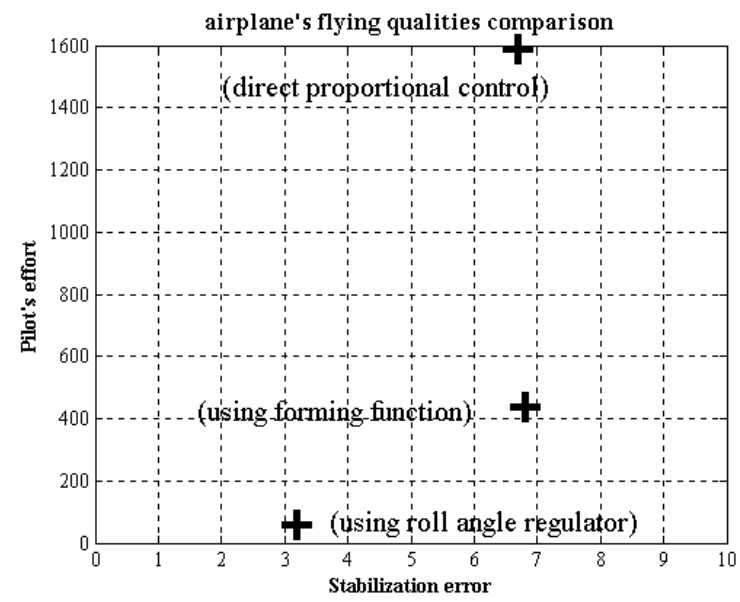

Fig 9. The comparison of aircraft handling qualities during course stabilization if tested control laws were used

Achieved results of control system grading needed to be confirm in another way. It seemed the simplest way of confirmation was to collect the opinion of the pilot about the handling qualities of an aircraft during tests. On the other side, it was interesting how the grade of the tested control system corresponded with pilot's feelings during flying by the airplane with modified handling characteristics.

Because of these reasons, pilots taking a part in tests were ordered to describe in their own words the handling 
qualities of the aircraft with the control system working in all of the tested modes. They also had to compare and classify the aircraft's handling qualities depending on tested control laws.

Generally it can be said that the opinion of pilots corresponded quite well with the results given by the method presented in this paper. Cases recognized by pilots as a having better handling qualities lay closer to the origin of the diagram then cases having worse ones.

Because of this, the method presented seems to be recognized as a mean which allows to compare handling qualities of the airplane equipped with the fly-by-wire control system supporting pilot's work.

\section{Conclusions}

During this research several flight tests have been done. They allowed checking the work of presented methods on normal operational conditions of the small transportation airplane. Those flights involved all typical maneuvers performed by pilots. The pilots, systemoperators had different levels of aviation experience and different levels of aviation qualifications therefore it can be said that reached results were reliable.

The comparison of achieved grades to pilots' opinions about airplane's handling qualities showed their high conformity.

A kind of universality of presented method should be pointed. It can be used to grade an aircraft's flying qualities during quite different maneuvers. Although, there are investigated quite different phenomena, the working algorithm is similar. For good evaluation of the control system two parameters should be considered. They are the pilot's effort factor and the parameter of control precision. Ways determining mentioned parameters are similar to each other for all investigated cases of maneuvers.

All the facts allow to formulate the statement that presented method can be used both to classify and to compare handling qualities of small airplanes equipped with fly-by-wire control system.

The results reached during flying tests allow formulating the opinion that the analyzed methodology of grading airplane's flying qualities can be taken under further investigation. In the future, investigations of the methodology presented should involve more statistical elements for greater group of pilots having different aviation experience.

\section{References}

1. Gruszecki J. Metody syntezy pokładowych systemów sterowania // Mechanika. Zeszyty Naukowe Politechniki Rzeszowskiej. - Rzeszów, 1995. - Vol 45.

2. Gruszecki J. Systemy sterowania i nawigacji bezzałogowych aparatów latających // Prace ZSS Politechniki Rzeszowskiej. Grant KBN No 9T12C 08212 i 9T12C 01108/TA. - Rzeszów, 1998.

3. Rogalski T. Kształtowanie wybranych właściwości eksploatacyjnych ogólnego przeznaczenia: Rozprawa doktorska na Wydziale Budowy Maszyn i Lotnictwa Politechniki Rzeszowskiej. Rzeszów, 2004.

4. Rogalski T. The conception of control system allowing to modify small aircraft's properties and simulate another plane's behavior // AIAA Conference and Exhibition. - Monterey, USA, 2002. - Paper No 3792

5. Rogalski T., Dołęga B. Aircraft control system enabling fly to everybody // Scientific Bulletins of Rzeszow University of Technology. - Rzeszów, 2004. - No 209. - P. 319-328.

6. Rogalski T., Dołęga B. The New Conception of The Laboratory Testing of the FBW Control Systems for Small Aircraft // Aircraft Engineering and Aerospace Technology. An International Journal. - Emerland, 2004. - No 3. - P.293-298.

7. Rogalski T., Rzucidło P., Tomczyk A. Kształtowanie właściwości pilotażowych samolotu z odległościowym układem sterowania. Symulacja w ujęciu nieliniowym // Mechanika w Lotnictwie. - Warszawa: PTMTS, 2002. - P. 411420. 